\title{
Salga seca e úmida de filés de pacu (Piaractus mesopotamicus)
}

\section{Dy and umided salting of fillets of pacu (Piaractus mesopotamicus)}

\author{
Jakeline Marcela Azambuja de Freitas ${ }^{1 *}$; Letícia Hayashi Higuchi²; Aldi Feiden; \\ Márcia Luzia Ferrarezi Maluf 4; Jackeline Marcante Dallagno15; Wilson Rogério \\ Boscolo $^{6}$
}

\section{Resumo}

O objetivo do presente estudo foi avaliar o processo da salga seca e salga úmida em filés de pacu (P. mesopotamicus), provenientes do cultivo em tanques-rede. Os filés com pele foram salgados na proporção de $40 \%$ de sal em relação ao peso inicial, por um período de 10 dias. Após processamento, foram avaliados os parâmetros microbiológicos e de composição centesimal dos filés submetidos a salga, bem como a determinação da concentração de cloreto de sódio $(\mathrm{NaCl})$ e cálculo de rendimento. Quanto à composição centesimal foram avaliados os teores de proteína, extrato etéreo, umidade e matéria mineral da matéria-prima in natura e nos produtos processados por salga. As análises microbiológicas compreenderam a determinação de coliformes a $45^{\circ} \mathrm{C}$, Salmonella sp e Staphylococcus coagulase positiva. Os pacus submetidos a salga úmida e seca mantiveram-se dentro dos padrões microbiológicos estabelecidos pela legislação. Os teores de umidade, proteína, lipídios e cloretos apresentaram diferenças $(p<0,05)$ entre os processos de salga. No entanto, ambas as formas podem ser utilizadas para o desenvolvimento de processos tecnológicos de baixo investimento incentivando novas opções para o consumo de pescado.

Palavras-chave: Conservação. Peixe nativo. Tecnologia do pescado. Processamento.

\begin{abstract}
The goal of this study was to evaluate the process of salting and dry salting of fillets in pacu (P. mesopotamicus), from cultivation in cages. Fillet with skin were salted at a rate of $40 \%$ of salt in relation of the initial weight, for a period of 10 days. After processing, were evaluated for microbiological and centesimal composition of fillets subjected to salting and determining the concentration of sodium chloride $(\mathrm{NaCl})$ and calculation of income. The centesimal composition were evaluated the protein, ether extract, moisture and ash of the raw material fresh and processed products by salting. The microbiological analysis included the determination of coliforms at $45^{\circ} \mathrm{C}$, Salmonella and Staphylococcus coagulase positive. The pacus subjected to umided and dry salting were within quality control standards established by the legislation. The content of umided, protein, lipids and chlorides showed differences $(p<0.05)$
\end{abstract}

1 Aluna do Programa de Pós-graduação em Zootecnia. Universidade Estadual do Oeste do Paraná, UNIOESTE. E-mail: jakelinemarcela@hotmail.com

2 Aluna do Programa de Pós-graduação em Aquicultura. Universidade Estadual Paulista Júlio de Mesquita Filho. E-mail: biologaleticiahh@hotmail.com

3 Prof. do curso de Engenharia de Pesca. Universidade Estadual do Oeste do Paraná, UNIOESTE. E-mail: aldifeiden@gmail.com

4 Pesquisadora do Grupo de Estudos de Manejo na Aqüicultura, Gemaq. Universidade Estadual do Oeste do Paraná, UNIOESTE. E-mail: mlfmaluf@yahoo.com.br

5 Pesquisadora do Grupo de Estudos de Manejo na Aqüicultura, Gemaq.Universidade Estadual do Oeste do Paraná, UNIOESTE. E-mail: jack.y.line@hotmail.com

${ }^{6}$ Prof. do Curso de Engenharia de Pesca. Universidade Estadual do Oeste do Paraná, UNIOESTE. E-mail: wilsonboscolo@, hotmail.com

* Autor para correspondência

Recebido para publicação 08/12/2009 Aprovado em 05/08/2010 
between the processes of salt. However both forms can be used for the development of technological processes of low investment by encouraging new options for fish consumption.

Key words: Conservation. Native fish. Fish technology. Processing.

\section{Introdução}

A carne de pescado é um produto de alto valor nutricional, rico em proteínas, lipídeos, minerais e vitaminas A, D e do complexo B (OGAWA, 1999). No entanto, é considerado um alimento altamente perecível (PRENTICE; SAINZ, 2005), devido a sua elevada atividade de água, gorduras insaturadas facilmente oxidáveis e $\mathrm{pH}$ próximo da neutralidade, condições estas que favorecem um excelente meio de cultura de microorganismos patogênicos (LANDGRAF, 2003).

Dessa forma, a implementação de diversas formas de processamento e conservação do pescado é condição necessária para agregar valor aos produtos e favorecer o maior consumo de produtos à base de peixe.

A salga é um dos métodos mais tradicionais de preservação de alimentos. É um processo relativamente simples, de fácil elaboração e baixo custo (PÉREZ et al., 2007). Está baseada no princípio da desidratação osmótica, em que o cloreto de sódio é a substância química utilizada (OLIVEIRA et al., 2008).

Durante o processo de salga, verifica-se a penetração do sal e conseqüente liberação de água da musculatura, diminuindo assim a atividade de água e criando condições impróprias para o desenvolvimento microbiano. Para garantir melhor conservação, ao final do processamento, o produto salgado é submetido a processos complementares, como secagem e/ou refrigeração (BARUFFALDI; OLIVEIRA, 1998).

Existem dois métodos principais de salga, a salga seca e úmida. A salga seca consiste no contato da matéria-prima direto com o cloreto de sódio (OLIVEIRA, 2007), favorecendo dessa forma uma maior desidratação do peixe, no entanto o pescado é mais susceptível a oxidação lipídica com o emprego desta técnica dado o contato do oxigênio com o produto (OGAWA et al., 1999).

Já a salga úmida é um processo onde a matériaprima é imersa em salmoura a uma concentração adequada. Neste processo a solução saturada de cloreto de sódio permanece no recipiente que contém o peixe o que garante uma baixa concentração de oxigênio no meio, protegendo a gordura do processo de oxidação (CARDOSO, 2003).

O pacu (P. mesopotamicus) é uma espécie nativa que apresenta crescimento rápido e boa aceitação pelo mercado consumidor (JOMORI et al., 2005), tornando-se uma espécie importante para a aquicultura brasileira (LIMA; OLIVEIRA; CONLON, 1999) e uma boa opção para utilização em processamento.

O presente trabalho teve como objetivo avaliar o rendimento, a composição centesimal e microbiológica do pacu (P. mesopotamicus), submetidos aos processos de salga úmida e seca.

\section{Material e Métodos}

Foram utilizados cinco pacus provenientes do cultivo em tanques-rede no Centro de Desenvolvimento de Tecnologias para Piscicultura em Tanques-rede, localizado no Refúgio Biológico do município de Santa Helena - PR, Brasil. Os peixes foram insensibilizados e acondicionados em gelo e água e transportados ao laboratório de Tecnologia do Pescado da Universidade Estadual do Oeste do Paraná - Campus - Toledo. Os quais foram eviscerados, descabeçados e lavados com água clorada (5 ppm) para remoção de sangue e vísceras.

Posteriormente, os peixes foram cortados longitudinalmente para obtenção de dez amostras. Os filés com pele (20 a $30 \mathrm{~mm}$ de espessura) foram submetidos ao processo de salga úmida e seca, com 
pesos médios iniciais de $367,73 \pm 26,23 \mathrm{~g}$ e 359,14 $\pm 103,20 \mathrm{~g}$, respectivamente, por um período de 10 dias.

Os peixes foram salgados, apenas uma única vez, na proporção de $40 \%$ de sal em relação ao peso inicial. No processo de salga úmida empregou-se salmoura saturada, utilizando sal fino (cerca de 1 $\mathrm{mm}$ ) enquanto para a salga seca utilizou-se $25 \%$ sal fino e $75 \%$ sal grosso (cerca de $5 \mathrm{~mm}$ ) para se evitar o fenômeno de "queima do sal" (BERKEL; BOOGAARD; HEIJNEN, 2005). O delineamento experimental foi inteiramente ao acaso com dois tratamentos e cinco repetições.

Após o processo de salga, para reduzir o teor de umidade a níveis adequados para a sua conservação, em torno de $45 \%$ de umidade conforme Ferreira et al. (2002), os peixes foram acondicionados em estufa com ventilação forçada a $55^{\circ} \mathrm{C}$ por 12 horas para secagem do produto. Posteriormente, foram pesados para realizar o cálculo de rendimento [(peso inicial - peso final)/peso inicial], análises de composição centesimal, microbiológica e determinação de cloretos.

Para análise de composição centesimal, foram avaliados os teores de proteína, extrato etéreo, umidade e matéria mineral da matéria-prima in natura e dos produtos submetidos a salga segundo as metodologias da AOAC (2000). Para avaliar as condições higiênico-sanitárias dos filés antes da salga e após a secagem, foram realizadas análises microbiológicas de coliformes a $45^{\circ} \mathrm{C}$, Staphylococcus coagulase positiva e Salmonella sp, segundo Silva, Junqueira e Silveira (2001). A determinação da concentração de cloreto de sódio foi obtida segundo as normas Analíticas do Instituto Adolfo Lutz (2005).

Os dados obtidos foram submetidos à análise de variância a $5 \%$ de probabilidade e em caso de diferenças significativas foi aplicado o teste de Tukey pelo programa estatístico computacional SAEG (Sistema de Análise Estatístico e Genético, UFV, 1997).

\section{Resultados e Discussão}

$\mathrm{Na}$ (Tabela 1) estão apresentados os resultados do rendimento e composição centesimal do pacu após processamento de salga seca e úmida.

Tabela 1. Rendimento e composição química do pacu submetido ao processo de salga úmida e seca.

\begin{tabular}{|c|c|c|c|c|}
\hline \multirow[t]{2}{*}{ Variáveis $^{1}(\%)$} & \multicolumn{3}{|c|}{ Tipos de salga } & \multirow[t]{2}{*}{ Pacu in natura } \\
\hline & Úmida & Seca & CV $(\%)$ & \\
\hline Rendimento & $72,98 \mathrm{a}$ & $72,16 \mathrm{a}$ & $3,53^{\mathrm{NS}}$ & - \\
\hline Umidade & $58,79 \mathrm{a}$ & $50,75 b$ & $4,53^{*}$ & 64,72 \\
\hline Proteínas & $16,22 b$ & $16,87 \mathrm{a}$ & $11,34^{*}$ & 17,56 \\
\hline Lipídeos & $13,12 b$ & $18,76 \mathrm{a}$ & $24,62 *$ & 16,59 \\
\hline Cinzas & $19,48 \mathrm{a}$ & $19,03 \mathrm{a}$ & $13,55^{\mathrm{NS}}$ & 2,92 \\
\hline Cloretos & $24,39 \mathrm{~b}$ & $25,27 \mathrm{a}$ & $18,66^{*}$ & - \\
\hline
\end{tabular}


Os resultados obtidos demonstraram que não houve diferenças $(p>0,05)$ nos filés de pacus quanto ao seu rendimento após o processo de salga úmida $(72,98 \%)$ e seca (72,16\%). Aiura et al. (2008) obtiveram para filés de tilápia-do-nilo, rendimentos de $19,3 \%$ para os produtos submetidos a salga em salmoura saturada após prensagem e secagem e de $14,2 \%$ para os filés submetidos ao processo de salga seca e secagem. No entanto, semelhantemente ao presente estudo, foi observado um rendimento menor do pescado quando submetido a salga seca. A abrangente faixa de rendimentos observada entre os trabalhos se deve provavelmente a forma de processamento do peixe, os exemplares de tilápia foram salgados na forma de filés (processo no qual há uma grande perda de rendimento), enquanto que os pacus foram apenas eviscerados e descabeçados. Além disso, os rendimentos do pescado salgado variam conforme a espécie utilizada, em função de variações nas concentrações de água intramuscular (SANTANA et al., 2009).

Conforme Faria et al. (2003) a tilápia apresenta rendimentos de filés com e sem pele $(39,21 \%$ e $36,44 \%$, respectivamente) inferiores ao do pacu $(51,60 \%$ e $46,73 \%$ para o filé com pele e sem pele), ao qual estão relacionados principalmente com a morfologia dos peixes. No caso do pacu esta espécie é descrita como fusiforme e peixes com esta característica tendem a apresentar maiores rendimentos devido à massa muscular cilíndrica que apresentam (CONTRERAS-GUSMÁN, 1994). Esses resultados indicam que o pacu $P$. mesopotamicus é uma espécie com grande potencial para o desenvolvimento de novas tecnologias de processamento.

Em relação ao teor de umidade, os valores obtidos foram significativos entre os diferentes tratamentos, em que se observou uma redução de $9,16 \%$ para a salga úmida e $21,58 \%$ para a salga seca, portanto sendo esta última a que apresentou uma redução mais intensa do teor de umidade.

No emprego da salga úmida, quando a concentração de sal situa-se acima de 15 a $18 \%$, a exemplo do presente estudo em que se utilizou um percentual elevado (40\%), ocorre redução da umidade por desidratação, porém a percentagem de água do peixe experimenta um acréscimo ao final do processo. Isto se deve a reabsorção de água pelo complexo sal/proteína, fenômeno ainda pouco esclarecido. Por outro lado, na salga seca a penetração do sal é mais intensa sendo que o conteúdo de umidade do produto diminui proporcionalmente com o incremento na penetração do sal, o que não possibilita a reidratação do pescado salgado (OGAWA et al., 1999).

Os valores apresentados para o teor lipídeos entre os dois processos de salga foram significativos $(\mathrm{p}<0,05)$. Observou-se um aumento do teor de lipídeos do filé quando submetido ao processo de salga seca (Tabela 1). Resultados semelhantes foram observados por Beirão et al. (1996) avaliando o processamento de salga seca de cação (Squatina argentina) e abrótea (Urophycis brasilienses), onde constataram uma elevação significativa no teor de lipídeos para as duas espécies.

Este fato pode estar relacionado com a retirada de água durante o processo de salga, pois como descrito por Ogawa e Maia (1999), existe uma inter-relação entre o teor de umidade e lipídeos nos tecidos dos peixes, ou seja, diminuindo-se a umidade aumentase o percentual de lipídeos. No entanto, para os produtos salgados em salmoura saturada, verificouse uma diminuição no teor de lipídeos $(13,12 \%)$ ao final do processamento, quando comparado com a matéria-prima in natura (16,59\%). Isso se deve possivelmente pelo emprego da salmoura, pois como observado o teor de umidade do pescado em salga úmida foi significativamente superior ao pescado salgado seco, $58,79 \%$ e $50,75 \%$, respectivamente.

Quanto ao teor de proteína observou-se diferença significativa $(p<0,05)$ entre os diferentes tratamentos, sendo que a salga seca apresentou maiores percentagens e, por conseguinte as menores reduções. No entanto, foram observados para os 
dois tipos de salga uma redução do teor de proteína quando comparado com a matéria-prima in natura.

Resultados semelhantes foram observados por Oliveira et al. (2008) que constataram uma redução do teor de proteínas do peixe mandim (Airus spixii) $(53,73 \%$ em base seca) quando submetido ao processamento de salga seca e secagem ao sol $(38,07 \%$ em base seca). Segundo Gava (1984) a adição do sal na musculatura promove a desnaturação de algumas proteínas, que se forem solúveis em solução salina, podem ser perdidas durante o processo de salga.

Para o teor de cinzas não foram observadas diferenças entre os dois tratamentos, no entanto constatou-se um incremento deste, quando comparado com a matéria in natura, em virtude da incorporação do sal na musculatura do pescado (OGAWA et al., 1999). Na matéria prima in natura foram encontrados valores de $2,92 \%$ de cinzas, enquanto que na salga seca e úmida este componente atingiu percentuais de $19,03 \%$ e $19,48 \%$, respectivamente. Semelhantemente, Szenttamásy et al. (1993) avaliando o processamento de salga seca do pacu, encontraram valores de 1,82\% nas amostras in natura e $17,76 \%$ nas salgado-secas.

Os valores do teor de cloretos obtidos foram significativos $(\mathrm{p}<0,05)$ entre os tratamentos, sendo observado um teor de $23,39 \%$ para a salga úmida e $25,27 \%$ para a salga seca, sendo esta significativamente superior. $\mathrm{O}$ carne do pescado apresenta teor de sal em torno de 0,08 a $1 \%$, no entanto este conteúdo eleva-se artificialmente através da aplicação de cloreto de sódio (GRECCHI, 1972), resultado da incorporação do sal na musculatura durante o processamento. Oliveira et al. (2008) encontraram valores de $17,02 \%$ de $\mathrm{NaCl}$ para o pescado salgado enquanto que o peixe in natura apresentou teores de $0,85 \%$, resultados estes semelhantes aos observados no presente estudo em que constatou-se um incremento no teor de cloretos dos filés após processados por salga.

Quanto os parâmetros microbiológicos, antes da salga e após a secagem (Tabela 2), os resultados encontraram-se abaixo dos valores estabelecidos pela legislação (ANVISA, 2001), indicando que para o peixe in natura, salgado seco e salgado em salmoura saturada estão em condições higiênicosanitário satisfatórias.

Tabela 2. Análise microbiológica do pacu in natura na salga úmida e seca.

\begin{tabular}{llccc}
\hline Parâmetros & Pacu in natura & $\begin{array}{c}\text { Legislação ANVISA } \\
\text { (peixe salgado) }\end{array}$ & Salga úmida & Salga seca \\
\hline $\begin{array}{l}\text { Salmonella } \mathrm{sp} \\
\text { Staphylococcus }\end{array}$ & Ausente & Ausente & Ausente & Ausente \\
$\begin{array}{l}\text { coagulase positiva } \\
\text { Coliformes } 45^{\circ} \mathrm{C}\end{array}$ & Ausente & $5 \times 10 \mathrm{UFC} / \mathrm{UFC} / \mathrm{g})$ & $<10 \mathrm{UFC} / \mathrm{g}$ & $<20 \mathrm{UFC} / \mathrm{g}$ \\
\hline
\end{tabular}

*UFC $=$ unidades formadoras de colônia.

*NMP = número mais provável.

No entanto, segundo Aiura et al. (2008) apesar de que o pescado salgado apresenta elevado teor de sal, estes produtos não estão livres de sofrer deterioração química ou microbiológica. Como observado na (Tabela 2), os filés de pacu submetidos a salga seca e úmida apresentaram contaminação microbiológica após o processamento, apesar de estarem em conformidade com a legislação.

Para os produtos salgados secos identificou-se uma população de S. aureus superior ao pescado salgado em salmoura saturada, apesar deste último 
apresentar o menor teor de umidade (Tabela 1).

Segundo Furtado et al. (1991) algumas bactérias, leveduras e fungos são capazes de crescer em concentrações salinas elevadas. Franco (1996) descreve que bactérias do gênero Staphylococcus podem multiplicar-se em 7,5 a 15\% de $\mathrm{NaCl}$. Dessa forma a identificação do patógeno nos produtos salgados, pode estar relacionado a limitação do efeito conservador do sal, ou ainda se deve provavelmente pelo pouco cuidado com a limpeza e desinfecção de superfícies ou por condições inadequadas na estocagem e conservação dos produtos (COSTA et al., 2008). Dessa forma para maior estabilidade dos produtos estes devem permanecer sob refrigeração.

Resultados semelhantes ao do presente estudo foram encontrados por Hilbig et al. (2008) que observaram estabilidade microbiológica dos produtos processados por salga e secagem, sendo constatado ausência de Staphylococcus coagulase positiva e Salmonella sp tanto para o peixe in natura quanto para o pescado processado por salga. A determinação do número mais provável para coliformes totais encontrados por esses autores foi observado somente para o pescado em seu estado cru $(15,3 \mathrm{NMP} / \mathrm{g})$, o que difere dos resultados obtidos no presente estudo ( $<3 \mathrm{NMP} / \mathrm{g}$ para salga e seca e úmida) apesar de estar em adequação com as normas exigidas.

Dessa forma, os pacus processados por salga mantiveram-se em adequação com as exigências impostas pela legislação, possibilitando desta forma viabilizar a sua comercialização e incentivar o consumo de produtos à base de pescado.

\section{Conclusão}

Os filés com pele salgados a seco e em salmoura saturada apresentaram boas condições higiênicas sanitárias e apresentaram diferentes rendimentos, podendo ser utilizados para o desenvolvimento de processos tecnológicos de baixo investimento incentivando novas opções para o consumo de pescado.

\section{Agradecimentos}

Aos convênios ITAIPU BINACIONAL/ UNIOESTE-GEMAq e SETI- Fundo Paraná/ UNIOESTE, pela disponibilização do material biológico e estrutura laboratorial e suporte técnico, respectivamente.

\section{Referências}

AGÊNCIANACIONAL DE VIGILÂNCIA SANITÁRIA - ANVISA. Resolução - RDC n ${ }^{\circ} 12$, de 02 de janeiro de 2001. Padrão microbiológico para alimentos. 2007. Disponível em: <http://www.anvisa.gov.br/legis/resl/1201rdc.html> Acesso em: 15 maio 2007.

AIURA, F. S.; CARVALHO, M. R. B.; VEIGAS, E. M. M.; KIRSCHNIK, P. G.; LIMA, T. M. A. Conservação de filés de tilápia-do-nilo (Oreochromis niloticus) em salga seca e úmida. Arquivo Brasileiro de Medicina Veterinária e Zootecnia, Belo Horizonte, v. 60, n. 6, p. 1521-1537, 2008.

ASSOCIATION OF OFFICIAL ANALYTICAL CHEMISTS - AOAC. Official Methods of Analysis of Official Analytical Chemists. 17. ed. Arlington: Inc., v. 1/2. 2000.

BARUFFALDI, R.; OLIVEIRA, M. N. Fundamentos de tecnologia de alimentos. São Paulo: Atheneu, 1998. 317 p.

BEIRÃO, L. H.; TEIXEIRA, E.; NORT, E.; BOING, S. M. C. Salga de cação (Squatina argentina) e abrótea (Urophycis brasiliensis). Boletim do Centro de Pesquisa de Processamento de Alimentos, Curitiba, v. 14, n. 1, p. 25-32, 1996.

BERKEL, B. M.; BOOGAARD, B. V. D.; HEIJNEN, C. Conservação de peixe e carne. 2005. Disponível em: $<$ http://www.anancy.net/documents/file_pt/12-p-2005screen.pdf.>. Acesso em: 16 jul. 2010.

CARDOSO, J. M. B. A pesca como alternativa para o desenvolvimento econômico do município de Calçoene, com implantação de um distrito industrial. 2003. Dissertação (Mestrado em Gestão Empresarial e de Negócios) - Faculdade de Macapá, Macapá.

CONTRERAS-GUSMÁN, E. S. Bioquímica de pescados e derivados. Jaboticabal: Funep, 1994.

COSTA, A. P. R.; ANDRADE, D. R.; VIDAL JÚNIOR, 
M. V.; CORDEIRO, C. A. M.; SOUZA, G.; ERTHAL JUNIOR, M.; SOUZA, C. L. M. Defumação de filés de piau-vermelho (Leporinus copelandii) com o uso de fumaça líquida. Revista Ceres, Viçosa, v. 55, n. 4. p. 251257, 2008.

FARIA, R. H. S.; SOUZA, M. L. R.; WAGNER, P. M.; POVH, J. A.; RIBEIRO, R. P. Rendimento do processamento da tilápia do Nilo (Oreochromis niloticus Linnaeus, 1757) e do pacu (Piaractus mesopotamicus Holmberg, 1887). Acta Scientiarum Animal Sciences, Maringá, v. 25, n. 1, p. 21-24, 2003.

FERREIRA, M. W.; SILVA, V. K.; BRESSAN, M. C.; FARIA, P. B.; VIEIRA, J. O.; ODA, S. H. I. Pescados processados: maior vida-de-prateleira e maior valor agregado. Lavras: Gráfica/UFLA, 2002. (Boletim de Extensão).

FRANCO, B. D. G. M. Importância dos microorganismos nos alimentos. In: FRANCO, B. D. G. M.; LANDGRAF, M. Microbiologia dos alimentos. São Paulo: Editora Atheneu, 1996. $182 \mathrm{p}$.

FURTADO, S. M. B.; SHIMOKOMAKI, S.; ROMANELLI, P. F.; RODRIGUES-AWAYA, D. B. Avaliação da qualidade da carne caprina salgada. Higiene Alimentar, Itapetininga, v. 5, n. 18, p. 34-38, 1991.

GAVA, A. J. Métodos de conservação de alimentos. In: Princípios de tecnologia de alimentos. São Paulo: Nobel, 1984. cap. 7, p. 280-281.

GRECCHI, D. Salga de peixe. Revista Nacional da Pesca, São Paulo, v. 14, n. 120, p. 10-13, 1972.

HILBIG, J.; ZABINE, L.; BANTLE, J. F.; RODRIGUES, S. L. C.; PASQUALI, R.; NASCIMENTO, I. A.; ALVES, G. Avaliação físico-química e microbiológica de tilápias submetidas a salga e secagem. In: ENCONTRO DE QUÍMICA DA REGIÃO SUL, 16., 2008, Blumenau. Anais eletrônicos... Blumenau: FURB, Universidade Regional de Blumenau, 2008. Disponível em: <http:// www.furb.br/temp_sbqsul/cdrom/index.php?page=traba lhos\&act=autores\#H>. Acesso em: 09 ago. 2010.

INSTITUTO ADOLFO LUTZ. Métodos físico-químicos para análise de alimentos. 4. ed. Brasília: Instituto Adolfo Lutz, 2005. 1018 p.

JOMORI, R. K.; CARNEIRO, D. J.; MARTINS, M. I. E. G.; PORTELLA, M. C. Economic evaluation of Piaractus mesopotamicus juvenile production in different rearing systems. Aquaculture, Amsterdam, v. 243, n. 1, p. 175183, 2005.

LANDGRAF, M. Deterioração microbiana de alimentos. In: FRANCO, B. D. G. M.; LANDGRAF, M. Microbiologia dos alimentos. São Paulo: Atheneu, 2003.
$182 \mathrm{p}$.

LIMA, J. A. F.; OLIVEIRA, B.; CONLON, J. M. Purification and characterization of insulin and petides derived from proglucagon and prosomatostatin from the fruit-eating fish, the pacu Piaractus mesopotamicus. Comparative Biochemistry Physiology. Part B, Biochemistry \& Molecular Biology, Canadá, v. 122, n. 1, p. 127-135, 1999.

OGAWA, M. O pescado como alimento. In: OGAWA, M.; MAIA, E. L. Manual de pesca, ciência e tecnologia do pescado. São Paulo: Livraria Varela, 1999. cap. 1, p. 3-5.

OGAWA, M.; NUNES, M. L.; OGAWA, N. B. P.; DINIZ, F. M.; OETTERER, M.; ITÓ, L. S.; MAIA, E. L. Tecnologia do pescado. In: OGAWA, M.; MAIA, E. L. Manual de pesca, ciência e tecnologia do pescado. São Paulo: Livraria Varela, 1999. cap. 16, p. 293-299.

OGAWA, M.; MAIA, E. L. Química do pescado. In: . Manual de pesca, ciência e tecnologia do

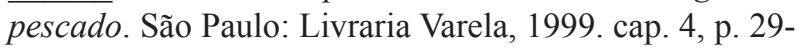
71.

OLIVEIRA, F. R. Avaliação do valor nutricional e ocorrência de óxidos de colesterol em peixe mandim (Aiurus spixii) comercializado em Maceió - AL. 2007. Dissertação (Mestrado em Nutrição) - Universidade Federal de Alagoas, Alagoas.

OLIVEIRA, F. R.; LIRA, M. G.; TORRES, E. A. F. S.; SOARES, R. A. M.; MENDONÇA, S.; SILVA, W. B.; SIMON, S. J. G. B.; SANTOS, T. M. P.; CABRAL JUNIOR, C. R. Efeito do beneficiamento sobre o valor nutricional do peixe mandim (Arius spixii). Revista Brasileira Ciências Farmacêutica, São Paulo, v. 44, n. 4, p. 655-667, 2008.

PÉREZ, A. C. A.; AVDOLOV, N.; NEIVA, C. R. P.; NETO, M. J. L.; LOPES, R. G.; TOMITA, R. Y.; FURLAN, É. F.; MACHADO, T. M. Procedimentos higiênico-sanitários para a indústria e inspetores de pescado: recomendações. 2007. Disponível em: <http:// www.gipescado.com.br/arquivos/minsp.pdf $>$. Acesso em: 03 dez. 2009.

PRENTICE, C. SAINZ, R. L. Cinética de deterioração apresentada por filés de carpa capim (Ctenopharyngodon idella) embalados a vácuo sob diferentes condições de refrigeração. Revista Ciência e Tecnologia de Alimentos, Campinas, v. 25, n. 1, p. 127-131, 2005.

SANTANA, F. M. S.; SANTOS, P. A. F.; LINS, L. H. C.; ARAÚJO NETO, E. T.; SILVA, S. L.; SILVA, B. C. L.; LIMA, H. C. Rendimento da tainha Mugil corema (Valenciennes, 1836) submetida ao processo de salga mista. In: JORNADA DE ENSINO PESQUISA 
E EXTENSÃO, 9., 2009, Recife. Anais eletrônicos... Recife: UFRPE, Universidade Federal Rural de Pernambuco, 2009. Disponível em: <http://www. eventosufrpe.com.br/jepex2009/cd/listaresumos.htm>. Acesso em: 09 ago. 2010.

SILVA, N.; JUNQUEIRA, V. C. A.; SILVEIRA, N. F. A. Manual de métodos de análise microbiológica de alimentos. São Paulo: Livraria Varela, 2001.

SZENTTAMÁSY, E. R.; BARBOSA, S. M. V. B.; OETTERER, M.; MORENO, I. A. M. Tecnologia do pescado de água doce: aproveitamento do pacu (Piaractus mesopotamicus). Scientia Agrícola, Piracicaba, v. 50, n. 2, p. 303-310, 1993.

UNIVERSIDADE ESTADUAL DE VIÇOSA - UFV. SAEG. Sistema para análises estatísticas e genéticas. Versão 7.1. UFV: Viçosa, MG. 1997. 150 p (Manual de Usuário). 